\title{
Parameters estimation of Drucker-Prager plasticity criteria for steel confined circular concrete columns in compression
}

\author{
Walid A. Al-Kutti \\ Department of Civil and Construction Engineering, College of Engineering, Imam Abdulrahman Bin Faisal \\ University, P.O. Box 1982, Dammam, Saudi Arabia.
}

Corresponding author: wasalem@iau.edu.sa

\begin{abstract}
This paper explores the possibility to use Drucker-Prager model in Steel-Concrete composite section. Numerical simulation was conducted using finite element package to simulate the steel-concrete composite section subjected to uniaxial compressive loading. After calibration with experimental study, parametric study was conducted to evaluate the effect of the friction angle and the cohesion constant $\mathrm{c}$ on the stress-strain curve of composite section. Empirical relationship between the friction angle and the confined concrete compressive strength was developed and a range of cohesion constant $\mathrm{c}$ between 5-10 MPa was suggested for confined concrete strength range of 25 to $100 \mathrm{MPa}$, respectively.
\end{abstract}

\section{Introduction}

A composite section is an element consisting of two materials with different properties. The idea of using two or more materials to build a composite element takes into account the advantages of both materials. One of the major composite elements is reinforced concrete in which the concrete material combines with steel to form a new composite material known as reinforced concrete, where the new material has the advantage of the high compression strength of concrete and the high tensile strength of steel. Although several experimental and numerical studies have been conducted on composite sections, there is a need to develop a simplified approach in modeling composite sections using Drucker-Prager plasticity criteria.

Several numerical studies have been conducted to simulate the behavior of confined concrete $[1,2]$. Jiang et al. [1] used ABAQUS software in their study and adopted the Drucker-Prager plasticity model, and concluded that the plastic dilation angle is a function of the axial plastic strain and the lateral stiffness ratio. Yu et al. [3] developed a modification of the Drucker-Prager plasticity model to predict the strength and ductility behavior of confined FRP concrete. Three features were mentioned in this study: a) the yield criterion including third deviatoric stress, b) a hardening/softening rule, which depends on the confining pressure, and c) the flow rule, which depends on the confining pressure and the rate of confinement increment. The model was implemented in ABAQUS software and a comparison between the numerical and experimental results was conducted.
Another approach was used by Dundar et al. [4] where an experimental study was conducted on the behavior of reinforced concrete columns and concreteencased composite columns subjected to biaxial bending and axial load. Fifteen reinforced concrete columns were subjected to both biaxial bending and axial load, and the nominal stress- strain relationship was used to model the concrete, steel and the reinforcing bars. The theoretical analysis and the experimental results showed that the compression strength of the concrete and its correspondent strain were the most important parameters on the ultimate strength of the composite columns.

In recent years, several researchers have used the Drucker-Prager model to simulate the behavior of concrete confined by FRP or steel tubes. Dian et al. [5] used the D-P plasticity model to simulate the behavior of a filled steel tube subjected to long term loading. The numerical results matched well with the experimental results. Similar work was reported by Ehab et al. [6] and Fa-xing et al. [7]. The main contribution of this paper will be developing an empirical estimation for the parameters of three Drucker-Prager plasticity criteria in confined concrete subjected to compression. The simplified approach will assist engineers and researchers to estimate the friction angle $\varphi$ and the cohesion constant $\mathrm{c}$ of confined concrete.

\section{Drucker-Prager Plasticity Model}

The 3-D concrete quarter cylinder was modeled as a 
perfect elasto-plastic Drucker-Prager material model, which includes the effect of hydrostatic pressure on the shearing resistance of the concrete. The Drucker-Prager yield criterion function $\mathrm{f}$ can be written as:

$$
f\left(I, \sqrt{J}_{2}\right)=\sqrt{J_{2}}+\alpha I=k
$$

where $I$ is the hydrostatic component of the stress tensor, $J_{2}$ is the deviatoric stress tensor invariant, $\alpha$ and $k$ are material constants which can be related to the friction angle $\varphi$, and cohesion $c$ of the modified Mohr-Coulomb by matching the outer apices of the $\mathrm{M}-\mathrm{C}$ hexagon with the D-P surface. For 3-D, the relation between the parameters is as follows:

$$
\begin{aligned}
& \alpha=2 \sin \varphi / \sqrt{3}(3-\sin \varphi) \\
& k=6 c \cos \varphi / \sqrt{3}(3-\sin \varphi)
\end{aligned}
$$

\section{Axial Load}
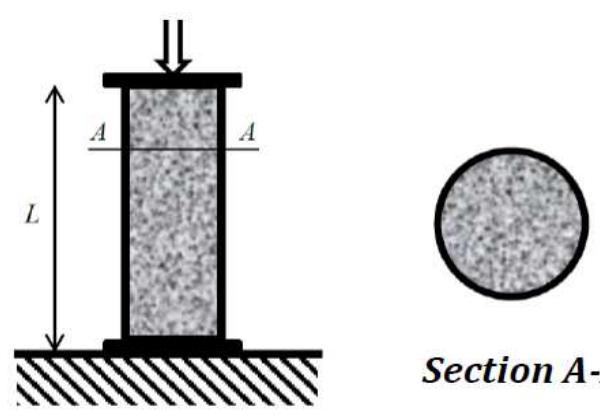

\section{Section $A-A$}

Fig 1. Experimental test setup.

\section{Experimental Model for Composite Section}

The Drucker-Prager model was calibrated with the experimental results reported by Sakino et al. [8]. Sakino et al. [8] investigated the effect of four parameters in composite sections subjected to uniaxial compressive load; these parameters were: (1) tube shape (circular and rectangular tubes), (2) tube tensile strength, (3) tube diameter-to-thickness ratio, and (4) concrete strength. A total of 114 composite steel short columns were subjected to uniaxial compressive load, and the average longitudinal strains were obtained from four linear variable differential transducers that measured axial deformation. Yielding of steel was the failure mode as reported in this experimental study. Figure 1 shows the experimental test setup used by Sakino et al. [8] including dimensions and boundary conditions of the specimen. The axisymmetric structural mechanics of boundary value problem can be used to simulate the stress-strain behavior of a composite section subjected to compression loading. Experimental results for circular concrete filled steel tubes reported by Sakino et al. [8] are used as a comparison with the numerical simulation using the finite element package software COMSOL and the Drucker-
Prager plasticity model. Details of the specimen dimensions and the material properties are shown in Tables 1 and 2 .

Table 1. Geometrical properties of the composite section [4]

\begin{tabular}{|c|c|c|c|}
\hline $\begin{array}{c}\mathrm{L} \\
(\mathrm{mm})\end{array}$ & $\begin{array}{c}\mathrm{D} \\
(\mathrm{mm})\end{array}$ & $\begin{array}{c}\mathrm{t} \\
(\mathrm{mm})\end{array}$ & $\mathrm{D} / \mathrm{t}$ \\
\hline 450 & 149 & 2.96 & 50.4 \\
\hline
\end{tabular}

Table 2. Mechanical properties of the composite section [4].

\begin{tabular}{|c|c|c|c|c|}
\hline $\begin{array}{c}\sigma_{\mathrm{y}} \\
(\mathrm{MPa})\end{array}$ & $\begin{array}{c}\sigma_{\mathrm{c}} \\
(\mathrm{MPa})\end{array}$ & $\begin{array}{c}\mathrm{N}_{\exp } \\
(\mathrm{kN})\end{array}$ & $\begin{array}{c}\sigma_{\mathrm{su}} \\
(\mathrm{MPa})\end{array}$ & $\begin{array}{c}\epsilon_{\mathrm{su}} \\
(\%)\end{array}$ \\
\hline 308 & 40.5 & 1043 & 340 & 1.21 \\
\hline
\end{tabular}

\section{(2)}

\section{Finite Element Model}

The axisymmetric structural mechanics of the boundary value problem with only one-eighth of the cylinder was used to simulate the stress-strain behavior of the composite section subjected to compression loading. An elasto-perfect plastic material was used for the steel tube in which the elastic modulus Es was about $200 \mathrm{GPa}$ and the yield strength $\sigma y$ was about $308 \mathrm{MPa}$. For concrete, a user defined expression function in COMSOL using the Drucker-Prager model, as defined in equations 1 and 2, was used for the concrete. The boundary condition was defined as a symmetrical plane for internal boundaries while it was defined as free for the curve boundary. The cohesion constant $\mathrm{c}$ was assumed to be $8.2 \mathrm{MPa}$, which is about $20 \%$ of the compressive strength of concrete $\sigma \mathrm{c}$ using the empirical formula for predicting direct shear test of concrete, as reported by Ha Ngoc Tuan et al. [9]; the friction angle $\varphi$ was $28^{\circ}$. These material parameters were found by calibration of the elasto-plastic solution for the uniaxial compression results experimentally determined by Sakino et al. [8], as mentioned in detail in section 3. The applied load was defined as increment axial displacement in the $\mathrm{z}$ direction from the top plane, and constraint conditions were applied in $\mathrm{x}$ and $\mathrm{y}$ directions. The yielding of steel is the failure mode as reported by Sakino et al. [8], and as predicted from the finite element model.

\section{Comparisons between DP Model and the Experimental Results}

Figure 2 shows a comparison between the numerical results analysis of the axisymmetric cylinder of a composite section using COMSOL and the DruckerPrager (DP) model, with the experimental results reported by Sakino et al. [8]. From Figure 2 it can be observed that the DP model matched well the experimental results of the confined can be noted in Figure 3, which shows the cross-sectional compression stress distribution at peak 
loading. From Figure 3 it can be observed that the maximum compression stress in the steel was found to be 318.5 MPa compared to $340 \mathrm{MPa}$ as shown in Table 1. From Figure 3, the compression stress in the confined concrete is about $55 \mathrm{MPa}$, which is approximately 1.4 times the compressive strength of unconfined concrete $(\sigma \mathrm{c}=40.8 \mathrm{MPa})$ as shown in Table 1 .

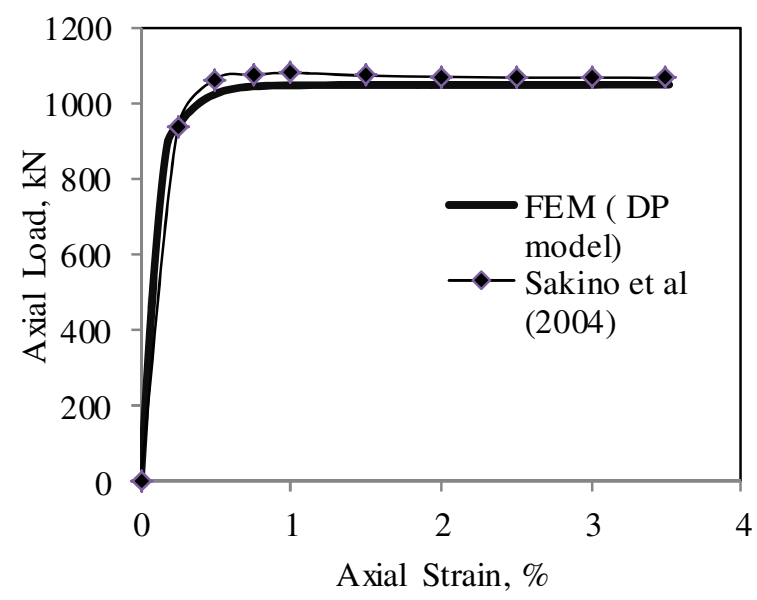

Fig 2. Comparison between numerical and experimental results.

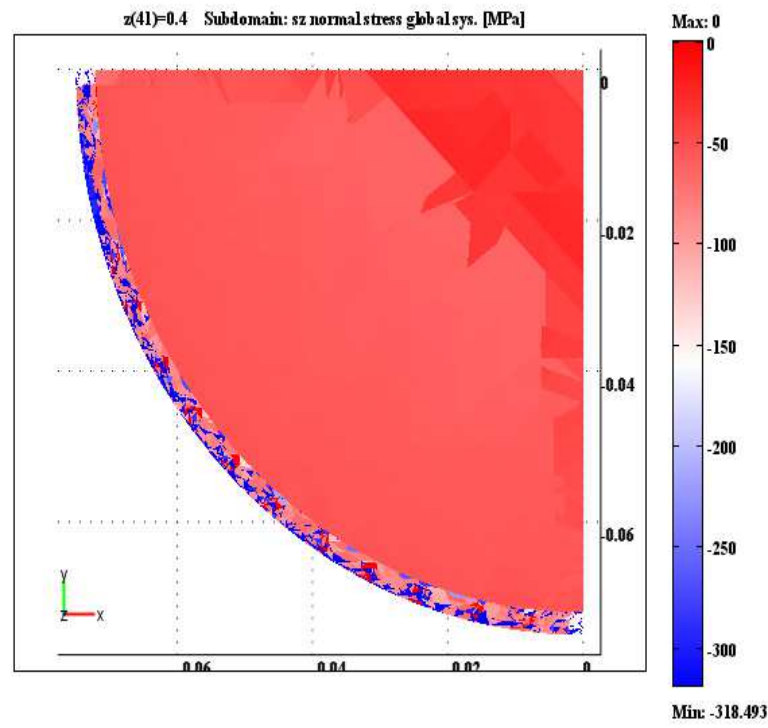

Fig 3. Compression stress distribution at peak loading.

\section{Parametric Study of Drucker-Prager Model Parameters}

To study the effect of friction angle $\varphi$ and cohesion $c$ on the confined compressive strength of concrete $\sigma \mathrm{cc}$, a parametric study was conducted. Figures 4 and 5 show the effect of the friction angle $\varphi$ and the cohesion $c$ on the axial compressive load of the composite section. Figure 4 shows the numerical solution for the axial load-strain of the composite section for constant friction angle $\varphi$ of $28^{\circ}$ and cohesion constant $\mathrm{c}$ of range between 1 and $10 \mathrm{MPa}$. From Figure 4 it can be observed that with the increase in $\mathrm{c}$, the peak load increases. However, for cohesion c of 1 $\mathrm{MPa}$, an elastic-perfect plastic relationship was observed, while for $\mathrm{c}$ values between 5 and $10 \mathrm{MPa}$, a more nonlinear relationship can be observed at the end of the elastic zone.

From these results it could be concluded that for normal concrete with compressive strength between 25 and $50 \mathrm{MPa}$, the cohesion constant $\mathrm{c}$ of range between 5 and $10 \mathrm{MPa}$ could be used, which about $20 \%$ of the unconfined compressive strength $\sigma c$.

Figure 5 shows the effect of the friction angle $\varphi$ on the behavior of confined concrete when using a cohesion constant $\mathrm{c}$ of $8.2 \mathrm{MPa}$. From Figure 5 it can be observed that the Drucker-Prager parameter of friction angle $\varphi$ affects the non-linearity behavior significantly when compared to the cohesion constant c, as shown in Figure 5. Higher values of $\varphi$ led to a higher peak load and more tendencies to catch the non-linearity at the end of the elastic zone. Based on the parametric study a relationship was developed between the friction angle $\varphi$ and the confined concrete compressive strength $\sigma \mathrm{cc}$, as shown in Figure 6. The exponential function was found to fit this relationship as follows:

$\sigma_{c c}=14.75 \exp ^{0.05 \varphi}$

For normal concrete with compressive strength between 25 and $50 \mathrm{MPa}$, the suitable friction angle $\varphi$ range was found to be between $15^{\circ}$ and $28^{\circ}$.

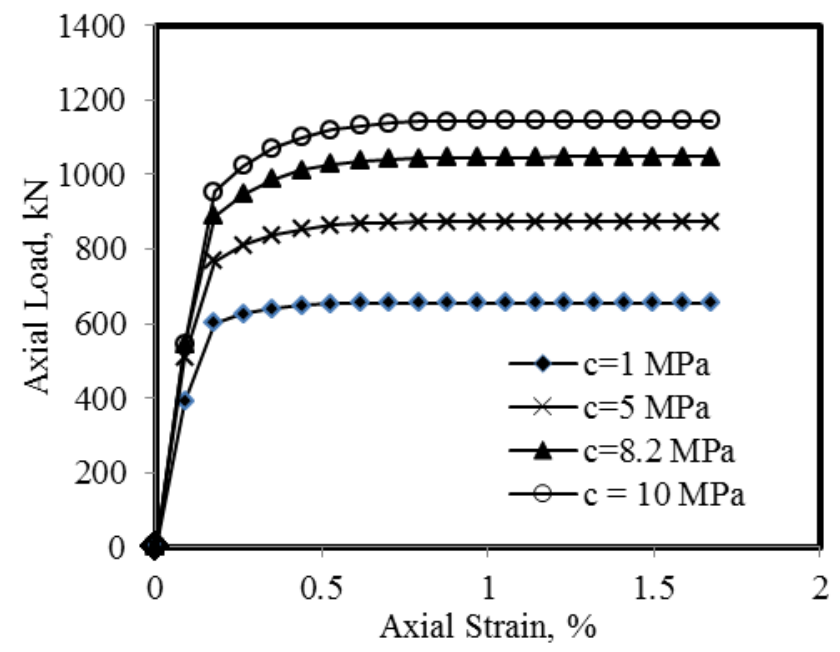

Fig. 4. Numerical simulation of axial load-strain for different values of cohesion constant $\mathrm{c}$ and friction angle $\varphi$ of $28^{\circ}$. 


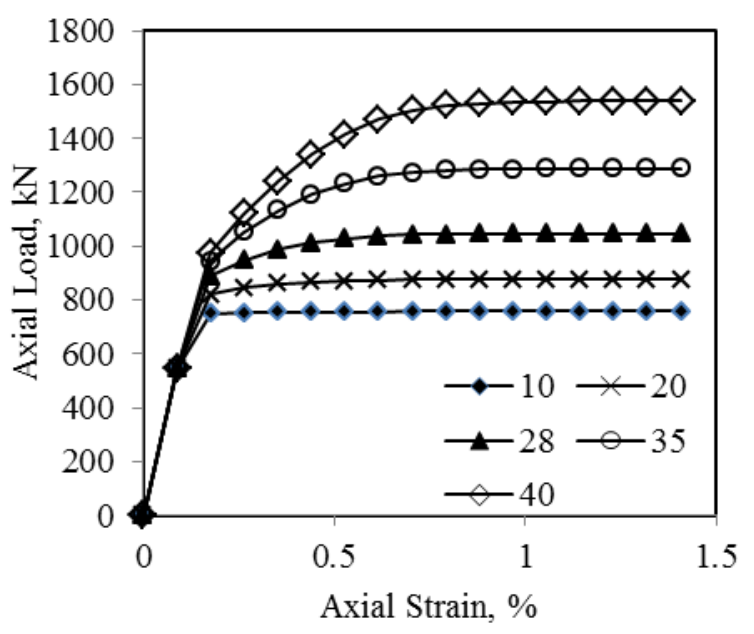

Fig 5. Numerical simulation of axial load-strain for different values of friction angle $\varphi$ with cohesion constant $c$ of 8.2 $\mathrm{MPa}$.

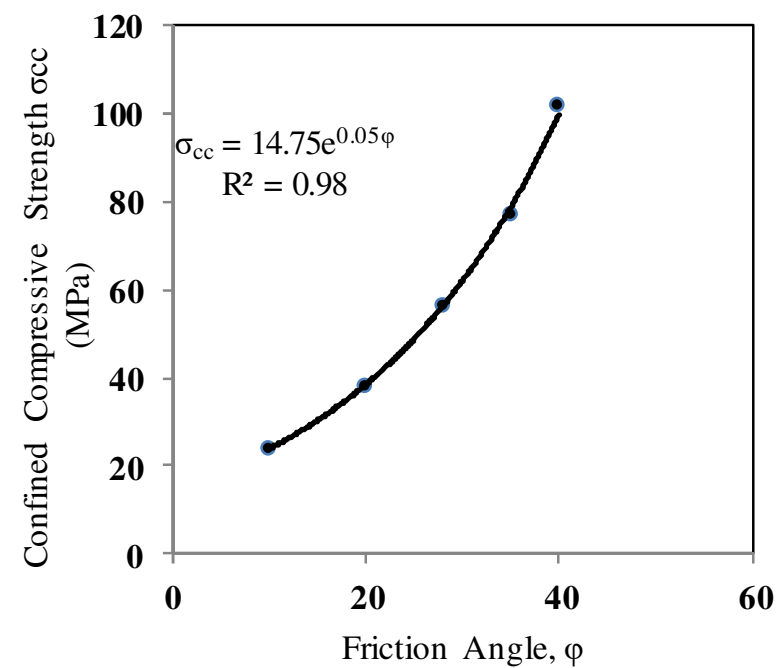

Fig 6. Relationship between the friction angle $\varphi$ with cohesion constant $\mathrm{c}$ of $8.2 \mathrm{MPa}$ and confined concrete compressive strength $\sigma_{\mathrm{cc}}$.

\section{Verification of the D-P plasticity model}

To verify the model, eleven concrete-filled-steel composite sections were cast and used for the testing. Eight of these steel tubes were cast with two types of concrete having different compressive strengths (25 and $43 \mathrm{MPa}$ ). Three steel tubes were tested without casting concrete to study the mechanical properties of steel tubes. The dimensions of the steel tubes were $300 \mathrm{~mm}$ in length, $100 \mathrm{~mm}$ in diameter (D) and $6 \mathrm{~mm}$ in thickness (t). The steel has yield strength of $360 \mathrm{MPa}$ and ultimate strength of $400 \mathrm{MPa}$ (see Fig.7). A comparison between the numerical results analysis of the axisymmetric cylinder of composite section using COMSOL and Drucker-Prager (DP) model with the experimental results reported is shown in Figure 8. From the data in Figure 8, it could be observed that the DP model matched well the experimental results of confined concrete section. Figure 8 shows that the peak load predicted by the FE analysis is about $10 \%$ higher than the experimental results.

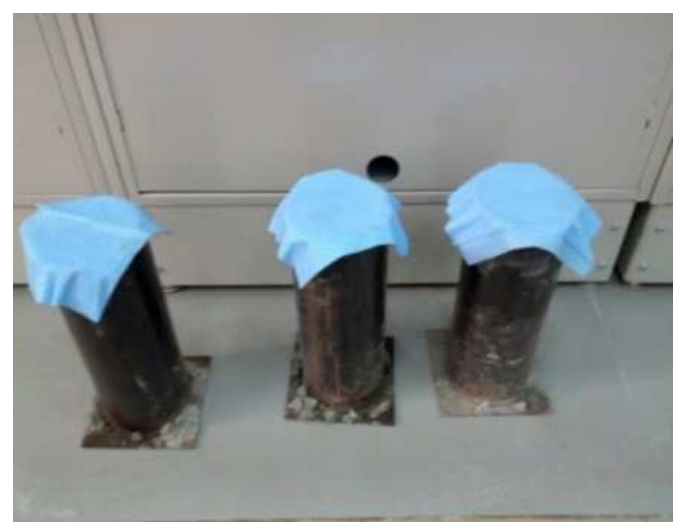

a) Curing of composite sections

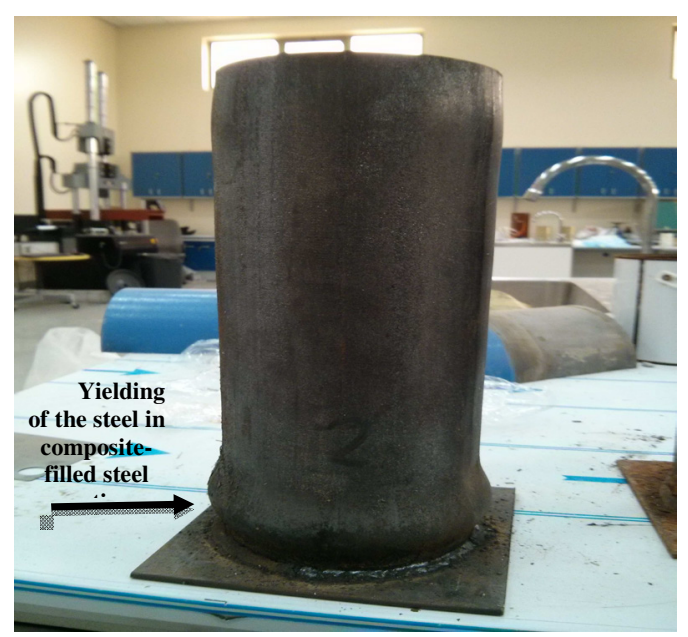

b) Failure mode

Fig. 7: Confined concrete-filled steel section, a) curing ; and $b$ ) failure mode.

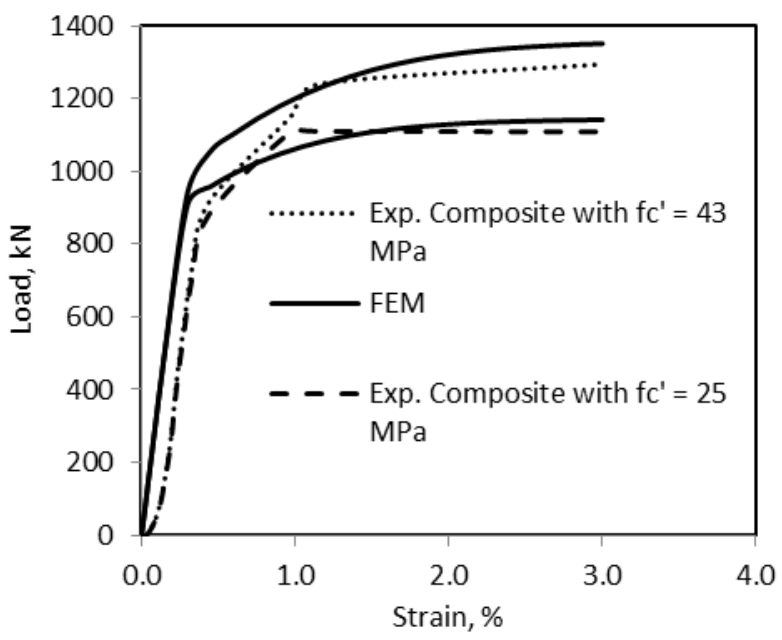

Fig 8. Comparison between numerical and experimental axial load-strain results for $\mathrm{fc}^{\prime}=25$ and $43 \mathrm{MPa}$. 


\section{Conclusions}

This paper provides a simple approach to estimate the Drucker-Prager model parameters to simulate the behavior of confined concrete subjected to compressive loading. Numerical simulation was conducted using COMSOL finite element package to simulate the steelconcrete composite section subjected to uniaxial compressive loading. The numerical simulation was calibrated by experimental results available in the literature. A numerical parametric study was conducted to evaluate the effect of the friction angle $\varphi$ and the cohesion constant $\mathrm{c}$ on the stress-strain curve of a steelconcrete composite section subjected to compressive stress. Higher values of $\varphi$ led to a higher peak load and more tendencies to catch the non-linearity of concrete at the end of the elastic zone. For cohesion constant $\mathrm{c}$ of 1 $\mathrm{MPa}$, an elastic-perfect plastic relationship was observed, while for $\mathrm{c}$ values between 5 and $10 \mathrm{MPa}$, a more nonlinear relationship was observed at the end of the elastic zone. Based on the numerical analysis, an empirical relationship between the friction angle and the confined concrete compressive strength was developed. For normal concrete with compressive strength between 25 and $50 \mathrm{MPa}$, the suitable friction angle $\varphi$ range was found to be between $15^{\circ}$ and $28^{\circ}$. and cohesion constant $\mathrm{c}$ of range between 5 and $10 \mathrm{MPa}$ could be used, which is about $20 \%$ of the unconfined compressive strength $\sigma c$. Further investigation should be conducted on the effect of the thickness, shape and dimension on the material parameters ( $c$ and $\varphi$ ) of the Drucker-Prager (DP) model. Besides, there is a need for further investigation considering high compressive strength.

\section{Acknowledgement}

This work was completed under the IAU university funded research project number DSR-2014175. The author acknowledges the support of the IAU, the Department of Civil and Construction Engineering, and Deanship of Scientific Research.

\section{References}

[1] J. Jia-Fei, Y. Wu, X. Zhao. Application of DruckerPrager plasticity model for stress-strain modeling of FRP confined concrete columns. Procedia Engineering, 14, 687-694, (2011)

[2] J. Jia-Fei, Y.F. Wu.. Identification of material parameters for Drucker-Prager plasticity model for FRP confined circular concrete columns. International Journal of Solids and Structures, 49, 445-456, (2012)
[3] T. Yu, J.G. Teng, Y.L. Wong, S.L. Dong. Finite element modeling of confined Concrete-I: Drucker Prager type plasticity model. Engineering Structures, 32, 665-679, (2010)

[4] D. Cengiz, S. Tokgoz, A. K. Tanrikulu, T. Baran. Behavior of reinforced and concrete-encased composite columns subjected to biaxial bending and axial load. Building and Environment, 43, 1109-1120, (2008)

[5] D.J. Zhang, Y.S. Ma, Y. Wang. Compressive behavior of concrete filled steel tubular columns subjected to long-term loading. Thin-Walled Structures, 89, 205-211. (2015)

[6] E. Ehab, Y. Ben. Numerical simulation of concrete encased steel composite columns. Journal of Construction Steel Research, 67, 2, 211-222, (2011)

[7] D. Fa-xing, Y. Zhi-wu, Y. Bai, Y.Z. Gong. Elastoplastic analysis of circular concrete-filled steel tube stub columns. Journal of Constructional Steel Research, 67, 1567-1577, (2011)

[8] K. Sakino, H. Nakahara, S. Morino, I. Nishiyama. Behavior of centrally loaded concrete-filled steel-tube short columns. ASCE Journal of Structural Engineering, 130, 2, 180-188, (2004)

[9] H.N. Tuan, H. Otsuka, Y. Ishikaw, E. Takeshita. A study on shear strength of concrete under direct shear test. Proceedings of the Japan Concrete Institute 28, 1, 1529-1534, (2006) 